\title{
Clinicopathological features of fibrosarcomatous dermatofibrosarcoma protuberans and the construction of a back-propagation neural network recognition model
}

Yanan $\mathrm{Li}^{1 \dagger}$, Jiaqi Liang ${ }^{2 \dagger}$, Xuewen $\mathrm{Xu}^{3}$, Xian Jiang ${ }^{4}$, Chuan Wang ${ }^{1}$, Siyuan Chen ${ }^{5}$, Bo Xiang ${ }^{1 *}$ and Yi $\mathrm{Ji}^{{ }^{1 *}}$ (D)

\begin{abstract}
Background: Fibrosarcomatous dermatofibrosarcoma protuberans (FS-DFSP) is a form of tumor progression of dermatofibrosarcoma protuberans (DFSP) with an increased risk of metastasis and recurrence. Few studies have compared the clinicopathological features of FS-DFSP and conventional DFSP (C-DFSP).

Objectives: To better understand the epidemiological and clinicopathological characteristics of FS-DFSP.

Methods: We conducted a cohort study of 221 patients diagnosed with DFSP and built a recognition model with a back-propagation (BP) neural network for FS-DFSP.

Results: Twenty-six patients with FS-DFSP and 195 patients with C-DFSP were included. There were no differences between FS-DFSP and C-DFSP regarding age at presentation, age at diagnosis, sex, size at diagnosis, size at presentation, and tumor growth. The negative ratio of CD34 in FS-DFSP (11.5\%) was significantly lower than that in C-DFSP (5.1\%) $(P=0.005)$. The average Ki-67 index of FS-DFSP (18.1\%) cases was significantly higher than that of C-DFSP (8.1\%) cases $(P<0.001)$. The classification accuracy of the BP neural network model training samples was $100 \%$. The correct rates of classification and misdiagnosis were $84.1 \%$ and $15.9 \%$.
\end{abstract}

Conclusions: The clinical manifestations of FS-DFSP and C-DFSP are similar but have large differences in immunohistochemistry. The classification accuracy and feasibility of the BP neural network model are high in FS-DFSP.

Keywords: Dermatofibrosarcoma protuberans, Fibrosarcomatous, Clinicopathological features, BP neural network

\section{Introduction}

Dermatofibrosarcoma protuberans (DFSP) is a rare and low-grade cutaneous soft tissue sarcoma with intermediate malignancy [1]. It is estimated that the incidence is

\footnotetext{
*Correspondence: xewkxb@sina.com; jijiyuanyuan@163.com

${ }^{\dagger}$ Yanan Li and Jiaqi Liang contributed equally to this work

${ }^{1}$ Division of Oncology, Department of Pediatric Surgery, West China

Hospital of Sichuan University, \#37 Guo-Xue-Xiang, Chengdu 610041, China

Full list of author information is available at the end of the article
}

approximately 0.8 to 5 cases per million per year [2, 3]. DFSP is most frequently observed in the Black race [4]. The male-to-female ratio is nearly 1:1 [5]. DFSP is usually diagnosed in adults in their $20 \mathrm{~s}, 30 \mathrm{~s}$ and $40 \mathrm{~s}[6,7]$ and mostly occurs on the trunk [8]. The local recurrence rate of DFSP is high, but the metastasis rate is low (approximately 2-5\%) $[3,9,10]$. Penner first described metastatic DFSP with fibrosarcomatous (FS) areas in 1951 [11]. The frequency of FS change according to histopathology may be $5 \%$ to $15 \%$ of DFSP cases, with a high rate of local and 
distant metastasis [12, 13]. It has been suggested that FS change might be a risk factor for local recurrence [14-17].

An artificial neural network (ANN) is an intelligent system that learns how the brain processes information by imitating the human nervous system. ANNs can make correct predictions of unknown data by learning and testing known data, and they do this by mathematically and physically abstracting and mimicking the structure and function of the human brain [18]. A back-propagation (BP) neural network is a kind of multilayer feedforward network that uses the error back-propagation algorithm. It has been reported that approximately $90 \%$ of neural networks are based on the BP algorithm, which has been widely used in disease recognition and diagnosis $[19,20]$.

Currently, few studies have reported the differences of conventional DFSP (C-DFSP, without fibrosarcomatous change) and FS-DFSP in the clinical features. In order to deeply understand the clinical characteristics of DFSP, we conducted a retrospective cohort study to evaluate the clinical characteristics of FS-DFSP and C-DFSP and build a recognition model with a $\mathrm{BP}$ neural network.

\section{Methods}

This study was a retrospective analysis of 221 patients with FS-DFSP (26) and C-DFSP (195) between 2010 and 2019 at the West China Hospital of Sichuan University. Approval was obtained from the West China Hospital of Sichuan University institutional review board. We got written informed consent from all patients or their parents when necessary. The diagnosis of DFSP was based on histological data. Clinical information, including sex, age at presentation, age at the time of first diagnosis, tumor size, location, histopathological findings, follow-up and outcome, was obtained. According to histopathology, we divided DFSP into two types: C-DFSP (Fig. 1a) and FSDFSP (Fig. 1b) [21].

Proportions were calculated for categorical variables, and means were calculated for continuous variables. The Pearson chi-square test and Fisher's exact test were used to analyze categorical variables. Continuous variables were analyzed by using Student's $t$-test. SPSS 25.0 for Windows (SPSS, Inc., Chicago, IL, USA) was used for statistical analyses. P values less than 0.05 indicated statistically significant results.

The Levenberg-Marquardt algorithm was provided in the MATLAB neural network to build a recognition model with a BP neural network. The number of input nodes for this study is 10 : $\mathrm{X} 0=\operatorname{sex}, \mathrm{X} 1=$ age at presentation, $\mathrm{X} 2=$ age at diagnosis, $\mathrm{X} 3=$ the interval of diagnosis, $\mathrm{X} 4=$ location, $\mathrm{X} 5=$ size at presentation, $\mathrm{X} 6=$ size at diagnosis, $\mathrm{X} 7=$ tumor growth, $\mathrm{X} 8=$ annual tumor growth, and $\mathrm{X} 9=$ growth type. The number of hidden neural nodes is 3 . The number of output layer nodes is 1 , corresponding to 1 for FS-DFSP and 0 for C-DFSP. The topological structure of the BP neural network is shown in Fig. 2.

\section{Results}

\section{Patient characteristics}

In total, 221 patients with a diagnosis of DFSP were included. All patients were Chinese. Table 1 presents the main clinical features of DFSP in this study. In our sample, there was a predominance of male patients, with a male-to-female ratio of 1:0.75. The peak incidence of DFSP at diagnosis was observed in patients in their $30 \mathrm{~s}$ to $50 \mathrm{~s}$ (Fig. 3a). The peak incidence of DFSP at presentation (the tumor was first noticed by the patient) was

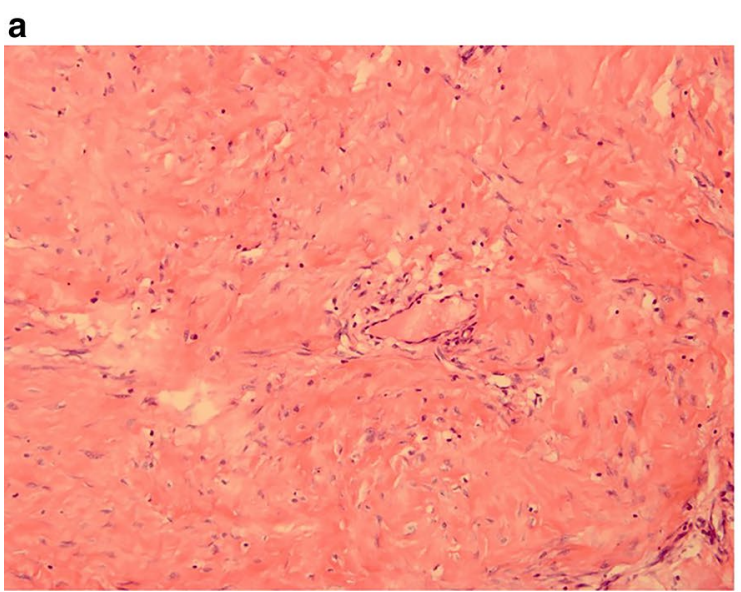

\section{b}

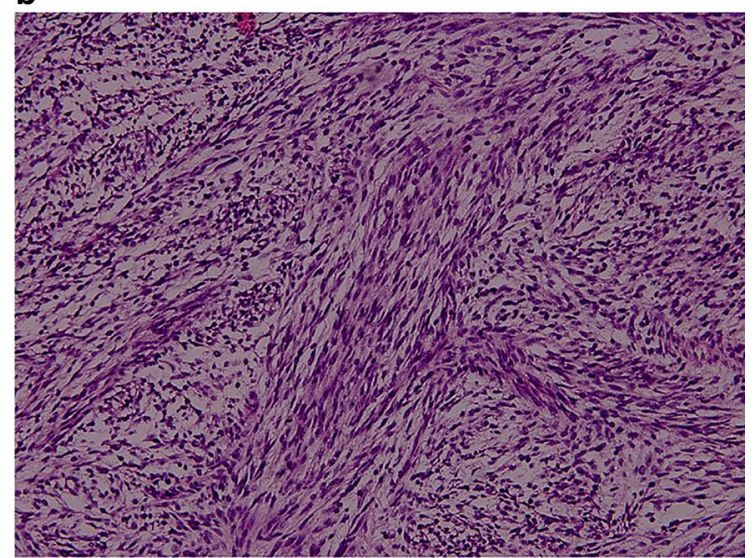

Fig. 1 Histopathological examination. a DFSP without fibrosarcomatous change showing spindle cells (H\&E, original magnification $\times 200)$. b DFSP with fibrosarcomatous change showing a fascicular growth pattern (H\&E, original magnification $\times 200)$ 


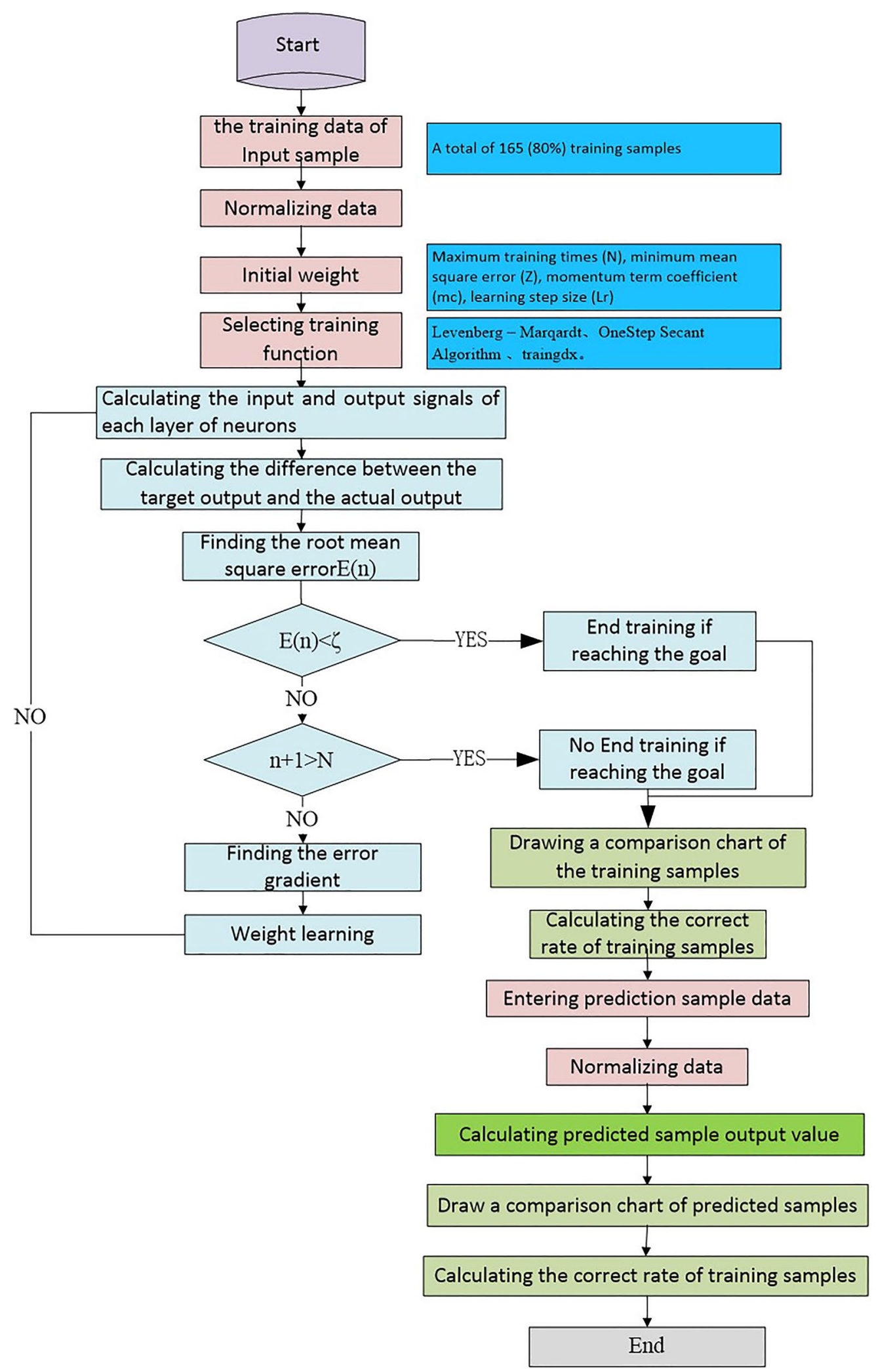

Fig. 2 The topological structure of the BP neural network 
Table 1 Clinical features of conventional and fibrosarcomatous DFSP

\begin{tabular}{|c|c|c|c|c|}
\hline Variables & $\begin{array}{l}\text { C-DFSP } \\
n=195\end{array}$ & $\begin{array}{l}\text { FS-DFSP } \\
n=26\end{array}$ & $\begin{array}{l}\text { Total } \\
n=221\end{array}$ & $P$ value \\
\hline \multicolumn{5}{|l|}{ Age at presentation (y) } \\
\hline Mean \pm SD & $30.7 \pm 14.4$ & $35.4 \pm 12.7$ & $31.24 \pm 14.23$ & 0.091 \\
\hline Median (range) & $30.0(0-66.0)$ & $36.5(12-57.0)$ & $30.25(0.0-66.0)$ & \\
\hline \multicolumn{5}{|l|}{ Age at diagnosis (y) } \\
\hline Mean \pm SD & $37.3 \pm 14.5$ & $40.5 \pm 10.3$ & $37.69 \pm 14.06$ & 0.168 \\
\hline Median (range) & $37.0(0.3-76.3)$ & $43.1(20.0-59.0)$ & $37.5(0.3-76.3)$ & \\
\hline \multicolumn{5}{|c|}{ The interval of diagnosis (y) } \\
\hline Mean \pm SD & $6.5 \pm 6.9$ & $5.1 \pm 6.5$ & $6.3 \pm 6.9$ & 0.302 \\
\hline Median (range) & $4.3(0-44.0)$ & $1.8(0.3-20.7)$ & $4.0(0-44.0)$ & \\
\hline Sex (male/female) & $108 / 87$ & $18 / 8$ & $126 / 95$ & 0.18 \\
\hline \multicolumn{5}{|c|}{ Size at presentation (cm) } \\
\hline Mean \pm SD & $1.1 \pm 1.0$ & $1.0 \pm 0.7$ & $1.07 \pm 1.05$ & 0.818 \\
\hline Median (range) & $1.0(0.2-10.0)$ & $1.0(0.1-3.0)$ & $1.0(0.1-10.0)$ & \\
\hline \multicolumn{5}{|l|}{ Size at diagnose } \\
\hline Mean \pm SD & $2.7 \pm 2.0$ & $3.1 \pm 1.7$ & $2.8 \pm 2.0$ & 0.362 \\
\hline Median (range) & $2.0(0.5-20.0)$ & $3.0(1.0-8.0)$ & $2.50(0.5-20.0)$ & \\
\hline \multicolumn{5}{|l|}{ Tumor growth } \\
\hline Mean \pm SD & $1.7 \pm 1.8$ & $2.0 \pm 1.7$ & $0.9 \pm 0.3$ & 0.337 \\
\hline Median (range) & $1.0(0-17.0)$ & $1.7(0-7.0)$ & $1.5(0-17.0)$ & \\
\hline \multicolumn{5}{|l|}{ Annual tumor growth } \\
\hline Mean $\pm S D$ & $0.9 \pm 2.9$ & $1.8 \pm 2.4$ & $0.97 \pm 2.84$ & 0.090 \\
\hline Median (range) & $0.3(0-37.5)$ & $0.7(0-9.3)$ & $0.3(0-37.5)$ & \\
\hline \multicolumn{5}{|l|}{ Location } \\
\hline Head-face-neck & $21(10.8 \%)$ & $5(19.2 \%)$ & $26(11.8 \%)$ & 0.272 \\
\hline Shoulder & $11(5.6 \%)$ & $2(7.7 \%)$ & $13(5.9 \%)$ & \\
\hline Chest & $51(26.2 \%)$ & $8(30.8 \%)$ & $59(26.7 \%)$ & \\
\hline Abdomen & $49(25.1 \%)$ & $3(11.5 \%)$ & $52(23.5 \%)$ & \\
\hline Posterior thighs & $40(20.5 \%)$ & $8(30.8 \%)$ & $48(21.7 \%)$ & \\
\hline Upper extremity & $11(5.6 \%)$ & $0(0)$ & $11(5.0 \%)$ & \\
\hline Lower extremity & $12(6.2 \%)$ & $0(0)$ & $12(5.4 \%)$ & \\
\hline \multicolumn{5}{|l|}{ Growth type } \\
\hline Indolence & $29(14.9 \%)$ & $1(3.8 \%)$ & $30(13.6 \%)$ & $<0.001$ \\
\hline Gradually increasing & $90(46.2 . \%)$ & $4(15.4 \%)$ & $94(42.5 \%)$ & \\
\hline Rapid enlargement & $76(38.9 \%)$ & $21(80.8 \%)$ & 97 (43.9\%) & \\
\hline \multicolumn{5}{|c|}{ Time to rapid enlargement (y) } \\
\hline Mean \pm SD & $5.3 \pm 6.5$ & $0.9 \pm 1.1$ & $4.4 \pm 6.0$ & 0.003 \\
\hline Median (range) & $4.0(0.1-41.0)$ & $0.6(0-5.0)$ & $3.0(0-41.0)$ & \\
\hline \multicolumn{5}{|l|}{ Cause } \\
\hline Trauma & 18 & 0 & 18 & 0.140 \\
\hline Unknown & $178(91.3 \%)$ & $26(100 \%)$ & $204(92.3 \%)$ & \\
\hline Pain & 29 & 2 & 31 & \\
\hline Metastasis & 0 & 1 & 1 & 0.118 \\
\hline Recurrence & 4 & 7 & 11 & \\
\hline \multicolumn{5}{|l|}{ Follow-up } \\
\hline Mean \pm SD & $4.8 \pm 2.2$ & $4.9 \pm 1.7$ & $4.8 \pm 2.1$ & 0.696 \\
\hline Median (range) & $4.6(1.8-16.6)$ & $4.6(1.9-8.6)$ & $4.6(1.8-16.6)$ & \\
\hline
\end{tabular}



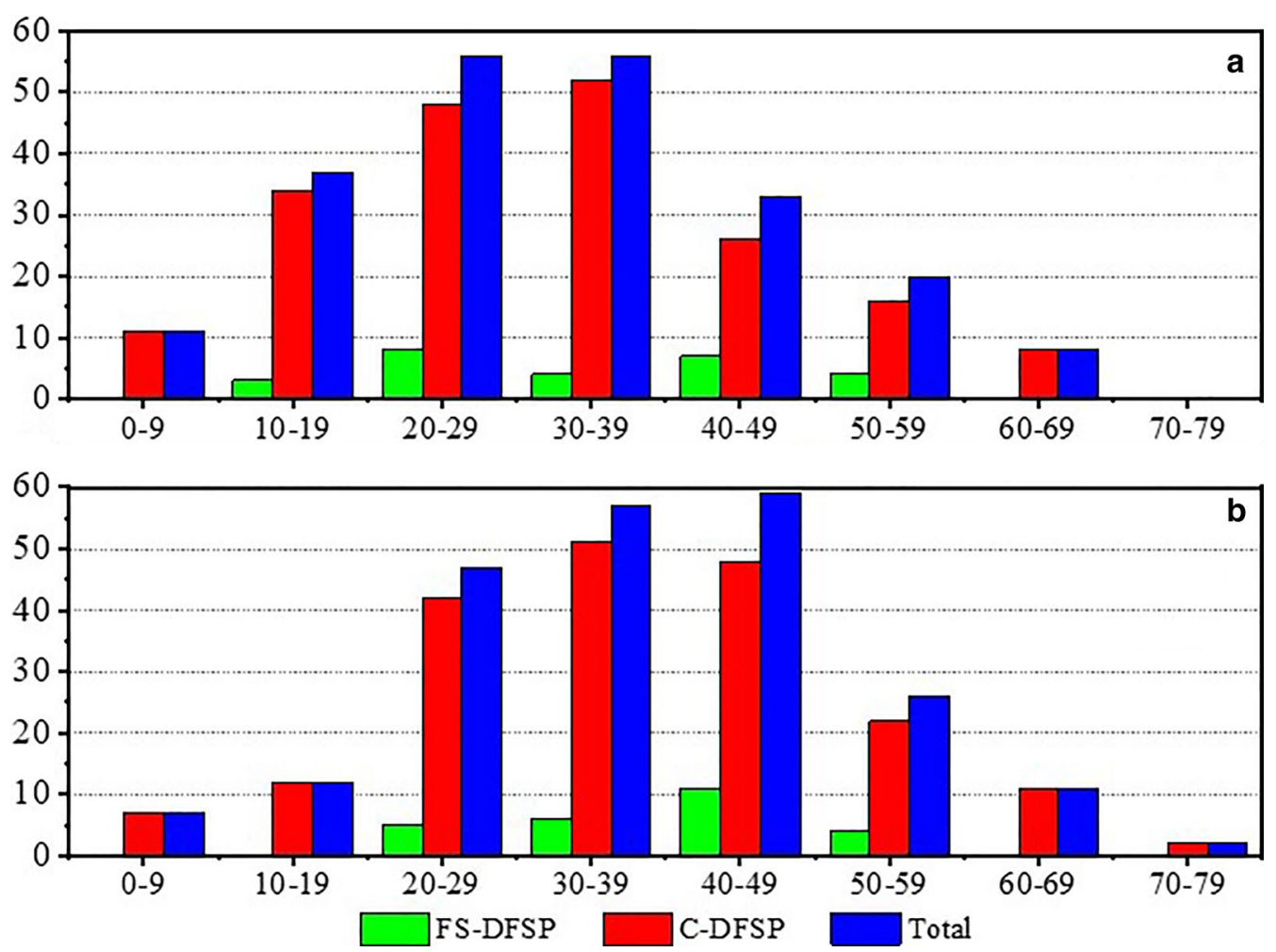

Fig. 3 Age distribution at presentation and first diagnosis in patients with FS-DFSP and C-DFSP (Y-axis: number of patients, X-axis: years). a Age at presentation; $\mathbf{b}$ age at first diagnosis

observed in patients whose ages ranged from 12 years to the sixth decade of life (Fig. 3b). DFSP mostly occurred on the chest $(26.7 \%)$. The "presumed" causes of the tumors were trauma $(8.1 \%)$ and unknown $(91.9 \%)$. In $43.9 \%$ of patients, the tumors were first indolent after discovery for a certain period of time but later grew rapidly. The median time to rapid enlargement (time from discovery of the tumor to rapid enlargement of the tumor) was 3.0 years. In $37.6 \%$ of patients the tumor size was persistently stable, and in $19.8 \%$ growth increased gradually. In most cases, patients $(86.0 \%)$ presented with a painless plaque, and only 31 patients (14.0\%) had painful masses.

\section{Comparison of clinical features between conventional and fibrosarcomatous DFSP}

C-DFSP mostly occurred on the chest (26.2\%), whereas FS-DFSP mostly occurred on the chest (11.8\%) and posterior thighs $(11.8 \%)$. Lung metastasis was found in only 1 FS-DFSP case. No differences in sex, age at presentation, age at the time of first diagnosis, interval between initial presentation and diagnostic confirmation, tumor size at the time of presentation, tumor size at the time of diagnosis, tumor growth, annual tumor growth or location were observed between C-DFSP and FS-DFSP. The annual tumor growth of FS-DFSP was significantly higher than that of C-DFSP, but there was no significant difference $(P=0.090)$.

\section{Immunohistochemistry}

CD34 staining was positive in $88.5 \%$ of FS-DFSP cases, whereas CD34 staining was positive in $99.5 \%$ of C-DFSP cases $(P=0.005)$ (Table 2$)$. There were no significant differences between the two groups regarding the standings of CD10, SMA or S100 $(P>0.05)$. P53 staining was negative in 24 FS-DFSP cases and 195 C-DFSP cases $(P=0.015)$. The Ki-67 average index was significantly higher in FS-DFSP than in C-DFSP $(P<0.001)$.

\section{The results of the BP neural network model}

The Levenberg-Marquardt algorithm can provide numerical solutions that minimize the number of nonlinearities (local minimums) with the fastest convergence speed (average 30 times). The number of hidden layers was 10 , the number of trainings was 31 , and the training target was 0.01 . The training sample classification accuracy was $100 \%$. The training sample misdiagnosis rate was 0 (Fig. 4a). In FS-DFSP, the test sample classification correct rate was $88.64 \%$, and the test sample misdiagnosis rate was $11.36 \%$. When training 31 times, the mean 
Table 2 Immunohistochemistry and fibrosarcomatous DFSP

\begin{tabular}{|c|c|c|c|}
\hline & NC-DFSP (195) & FS-DFSP (26) & $P$ value \\
\hline \multicolumn{4}{|l|}{ CD34 } \\
\hline Negative & 1 & 3 & \multirow[t]{2}{*}{0.005} \\
\hline Positive & 194 & 23 & \\
\hline \multicolumn{4}{|l|}{ CD10 } \\
\hline Negative & 27 & 2 & \multirow[t]{3}{*}{-} \\
\hline Positive & 24 & 24 & \\
\hline Unknown & 144 & 0 & \\
\hline \multicolumn{4}{|l|}{ SMA } \\
\hline Negative & 193 & 26 & \multirow[t]{2}{*}{1.000} \\
\hline Positive & 2 & 0 & \\
\hline \multicolumn{4}{|l|}{ Desmin } \\
\hline Negative & 194 & 26 & \multirow[t]{2}{*}{-} \\
\hline Positive & 0 & 0 & \\
\hline \multicolumn{4}{|l|}{$S 100$} \\
\hline Negative & 194 & 26 & \multirow[t]{2}{*}{1.000} \\
\hline Positive & 1 & 0 & \\
\hline \multicolumn{4}{|l|}{ P53 } \\
\hline Negative & 195 & 24 & \multirow[t]{2}{*}{0.015} \\
\hline Positive & 0 & 2 & \\
\hline \multicolumn{4}{|l|}{ EMA } \\
\hline Negative & 195 & 26 & \multirow[t]{2}{*}{-} \\
\hline Positive & 0 & 0 & \\
\hline Ki-67 & $8.1 \pm 4.7$ & $18.1 \pm 12.2$ & $<0.001$ \\
\hline
\end{tabular}

square error was 0.01 , which reached the target value (Fig. 4b).

\section{Discussion}

In the current study, a large number of patients were assessed the clinical features of C-DFSP and FS-DFSP. Our results indicate no significant difference between patients with C-DFSP and FS-DFSP in terms of sex, age at presentation, age at the time of first diagnosis, interval from initial presentation to diagnostic confirmation, tumor size at the time of presentation, tumor size at the time of diagnosis, tumor growth, or annual tumor growth. Interestingly, compared with that of recurrent C-DFSP, the annual tumor growth of FS-DFSP was higher, although there was no significant difference.

Recent studies have revealed that the frequency of FS according to histopathology may be approximately $5 \%$ to $15 \%$ of all DFSP cases $[12,13]$. Similar to previous studies, we found that FS-DFSP represented $11.7 \%$ of all DFSP cases. Connelly et al. reported that the median age of FS-DFSP patients was significantly higher than that of C-DFSP patients [22]. In the current study, we found that the median age of patients with FS-DFSP was only slightly higher than that of patients with C-DFSP. Many studies have reported that DFSP is generally diagnosed between the ages of 20 and 40 years. However, few studies have indicated the age at presentation of DFSP $[6,7$, 21]. We found that there were some differences in the age at presentation of DFSP between the two groups. In our study, the peak incidence of FS-DFSP at presentation was observed in patients in their $20 \mathrm{~s}, 30 \mathrm{~s}, 40 \mathrm{~s}$ and $50 \mathrm{~s}$, whereas the peak incidence of C-DFSP at presentation
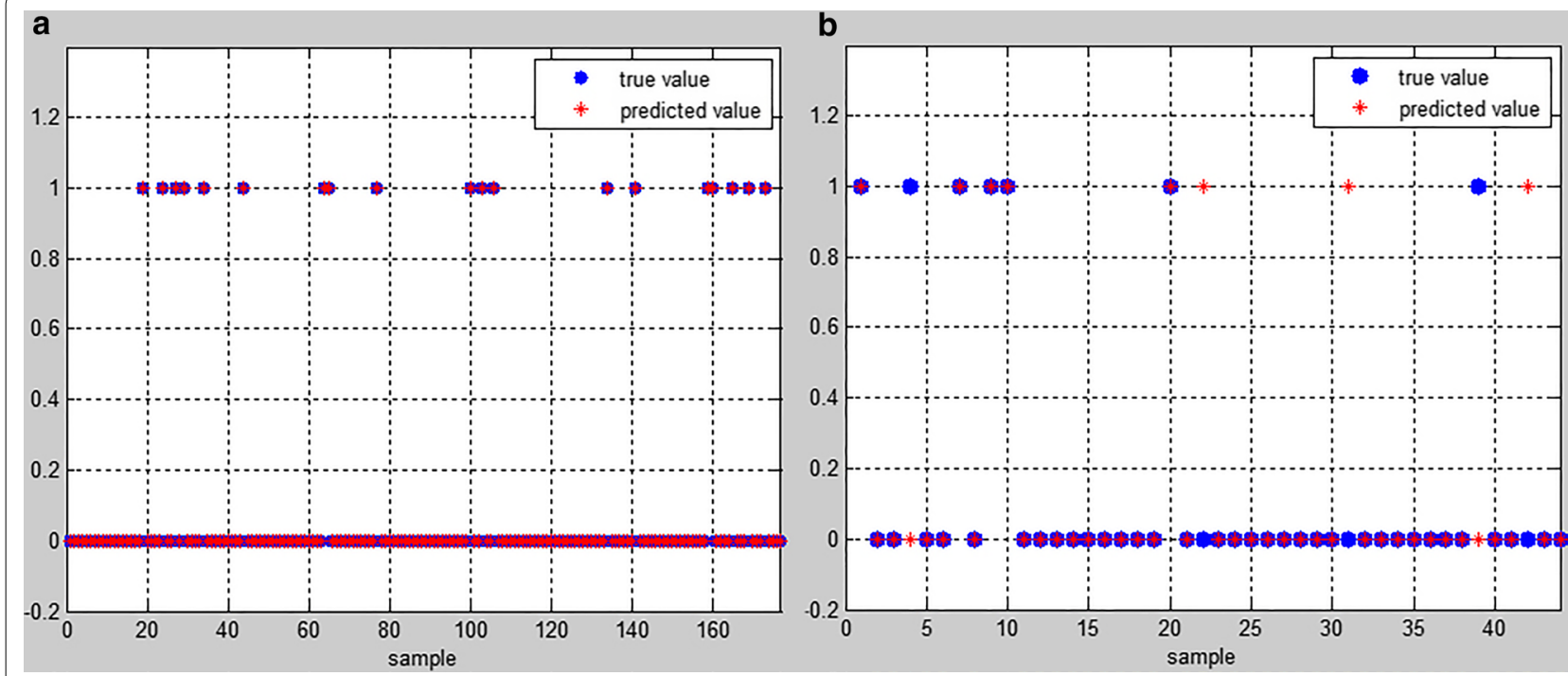

Fig. 4 The results of the BP neural network model: $\mathbf{a}$ the result of the training set; $\mathbf{b}$ the result of the test set 
was observed in patients aged 12 years to the 6th decade of life.

DFSP can occur anywhere in the body. We found that FS-DFSP mostly occurred on the chest and posterior thighs, whereas C-DFSP mostly occurred on the chest. Currently, the correlation between DFSP incidence and sex remains unclear. Bowne et al. reported that the male-to-female ratio was nearly 1:1 [5]. Other studies reported a slight predominance of female patients [4, 23]. In the current study, however, we observed that there was a predominance of male patients in FS-DFSP and C-DFSP. Correlations with prior trauma, surgical or burn scars, which had been reported in approximately $10 \%$ of DFSP cases, were unclear $[24,25]$. In our series, trauma induced DFSP in $8.1 \%$ of patients.

Clinically, DFSP often presents as an indolent tumor [26]. In the current study, we found that some lesions can be indolent, whereas others can grow slowly or show rapid enlargement after a period of indolence. Interestingly, FS-DFSP had a significantly shorter time from indolence to rapid enlargement. FS changes have not been reported in children with DFSP [27-30]. Interestingly, the tumors of two patients with FS-DFSP presented in childhood. The age of one patient was 12 years, and that of the other was 15 years. There is evidence suggesting that FS-DFSP may be an evolution of C-DFSP. Previous studies have demonstrated that P53 and MDM2 are overexpressed in FS-DFSP. In addition, activation of Akt/ mTOR, STAT3, ERK and PD-L1 may be related to the development or progression of DFSP [21, 31, 32].

Previously, the wide local excision (WLE) was the gold standard treatment for DFSP, with a recurrence rate ranging from 0 to $41 \%$ [33]. Recently, Mohs micrographic surgery (MMS) has been proven to be an alternative to WLE that assesses $100 \%$ of the margins with maximum tissue conservation. Many studies comparing the recurrence rate of WLE and MMS for the treatment of DFSP have shown that the recurrence rate after MMS ranges from 0 to 6.7\% [34-38]. Although the most adequate surgical method (i.e., MMS or WLE) for the treatment of DFSP remains controversial, there is evidence suggesting that MMS has lower rates of recurrence $[23,34,39]$. In some cases, DFSP might receive a simple excision because it is misdiagnosed as a benign mass, with high local recurrence (26-60\%) [40]. FSDFSP is highly aggressive and related to a high risk of local recurrence $[13,15]$. FS changes can be commonly identified in primary tumors. In several studies, however, FS changes were detected only in recurrent tumors [12, 41]. Interestingly, our previous study showed that the proportion of FS-DFSP in the recurrent DFSP was higher than the primary DFSP [17]. In a multicenter study, Eva A et al. revealed that after WLE, patients with FS-DFSP more often experienced recurrence than those with C-DFSP [14]. In our recent study, we found that after MMS, FS change was an independent prognostic factor for local recurrence in both univariable and multivariable analyses [14].

It has been reported that $92-100 \%$ of DFSP cases usually show diffuse CD34 staining, can be positive for vimentin, nestin and apolipoprotein $\mathrm{D}$, and can be negative for cytokerins, smooth muscle actin smooth muscle actin, S100, CD56, factor XIIIa, Stromelysin 3 and cathepsin $K[24,25,42]$. CD34 is reported to be negative in up to $50 \%$ of DFSP in FS-DFSP [43]. In the current study, the negative ratio of CD34 in FS-DFSP was significantly lower than that in C-DFSP. Sasaki indicated that the $\mathrm{Ki}-67$ index in FS-DFSP is significantly higher than the Ki-67 index in C-DFSP (C-DFSP: $8.9 \%$ vs FS-DFSP: $21.5 \%$ ) [44]. Similarly, in our study, the average Ki-67 index in FS-DFSP cases was significantly higher than that in C-DFSP cases (C-DFSP: $8.1 \%$ vs FS-DFSP: $18.1 \%)$. As a nuclear protein, Ki-67 is related to ribosomal RNA synthesis and has an essential function in cell proliferation. Khor et al. indicated that a high index of Ki-67 in prostate cancer was related to an increased risk of distant metastasis, cancer-specific mortality and overall death [45]. Several studies have shown that high Ki-67 levels were correlated with an obviously worse overall survival rate in mantle-cell lymphoma $[46,47]$

The BP neural network is a kind of multilayer feedforward network that uses the error back-propagation algorithm. The BP neural network was first proposed by Paul Werbos in 1974, but it has not been widely recognized. In the 1980s, Rumelhar et al. renamed the BP algorithm, which was included in "Parallel Distributed Processing" [48-51]. Recently, the BP algorithm became the most widely used algorithm in neural networks. It was reported that approximately $90 \%$ of neural networks were based on the BP algorithm $[19,20]$. At present, the BP neural network is widely used in disease recognition and diagnosis $[19,20]$. In the present study, when the number of invisible layers is 10 , the Levenberg-Marquardt algorithm can complete the learning of the entire training set sample size in 31 runs. The correct rates of classification and misdiagnosis were $84.1 \%$ and $15.9 \%$, respectively. The classification accuracy and feasibility of the BP neural network model are high in FS-DFSP.

The retrospective nature of this research is the main limitation of the current study. In addition, long-term follow-up data were lacking in the current study. Nonetheless, this is one of the largest studies of DFSP, and despite its limitations, our study can provide valuable information to aid in clinical practice. 


\section{Conclusion}

Although the clinical characteristics of FS-DFSP might resemble those of C-DFSP, FS-DFSP usually occurs in older patients. In contrast to that in C-DFSP, the expression of CD34 in FS-DFSP tumor tissues is negative. The $\mathrm{Ki}-67$ index in FS-DFSP is significantly higher than the Ki-67 index in C-DFSP. The BP neural network model constructed by the Levenberg-Marquardt algorithm has a high classification accuracy and feasibility for FSDFSP and may be used as a method for clinical auxiliary identification.

\section{Abbreviations \\ DFSP: Dermatofibrosarcoma protuberans; C-DFSP: Conventional dermatofi- brosarcoma protuberans; FS-DFSP: Fibrosarcomatous dermatofibrosarcoma protuberans; ANN: An artificial neural network; BP: Back-propagation.}

\section{Acknowledgements}

This project was supported by grants from the National Natural Science Foundation of China (Grants 81400862 and 81401606), the Key Project in the Science and Technology Program of Sichuan Province (Grant 2019YFS0322), the Science Foundation for The Excellent Youth Scholars of Sichuan University (Grant 2015SU04A15), and the 1.3.5 Project for Disciplines of Excellence-Clinical Research Incubation Project, West China Hospital of Sichuan University (grant numbers 2019HXFH056 and 2020HXFH048).

\section{Authors' contributions}

Conceptualization: XX, XJ, YJ and BX. Investigation: YL, JL, CW and SC. Data curation: $Y L$ and JL. Writing: $Y L$ and JL. All authors read and approved the final manuscript.

\section{Funding}

This work was supported by the National Natural Science Foundation of China (Grant numbers 81400862 and 81401606), the Key Project in the Science and Technology Program of Sichuan Province (grant number 2019YFS0322), the Science Foundation for The Excellent Youth Scholars of Sichuan University (Grant number 2015SU04A15), and the 1.3.5 Project for Disciplines of Excellence-Clinical Research Incubation Project, West China Hospital of Sichuan University (Grant numbers 2019HXFH056 and 2020HXFH048).

\section{Availability of data and materials}

The datasets used and/or analyzed during the current study available from the corresponding author on reasonable request.

\section{Ethics approval and consent to participate}

The study was approved by the Ethics Committee of the West China Hospital of Sichuan University. Written informed consent was obtained from the patients' parents, according to the provisions of the Declaration of Helsinki.

\section{Consent for publication}

Written informed consent for publication this study was obtained from the patients' parents. Copies of the signed informed consent forms are available for review by the Series Editor of BMC Pediatrics.

\section{Competing interests}

The authors declare that they have no competing interests, either financial or non-financial, that could be perceived as prejudicing the impartiality of the research reported.

\section{Author details}

1 Division of Oncology, Department of Pediatric Surgery, West China Hospital of Sichuan University, \#37 Guo-Xue-Xiang, Chengdu 610041, China. ${ }^{2}$ Shaanxi Zhongtian Rocket Technology Co, Ltd, Xi'an 710025, China. ${ }^{3}$ Department of Burns and Plastic Surgery, West China Hospital of Sichuan University, Chengdu 610041, China. ${ }^{4}$ Department of Dermatology, West China Hospital of Sichuan University, Chengdu 610041, China. ${ }^{5}$ Pediatric Intensive Care Unit,
Department of Critical Care Medicine, West China Hospital of Sichuan University, Chengdu 610041, China.

Received: 7 October 2020 Accepted: 19 January 2021

Published online: 26 January 2021

\section{References}

1. Mendenhall WM, Zlotecki RA, Scarborough MT. Dermatofibrosarcoma protuberans. Cancer. 2004;101(11):2503-8.

2. Bendix-Hansen K, Myhre-Jensen O, Kaae S. Dermatofibrosarcoma protuberans. A clinico-pathological study of nineteen cases and review of world literature. Scand J Plast Reconstr Surg. 1983;17(3):247-52.

3. Criscione VD, Weinstock MA. Descriptive epidemiology of dermatofibrosarcoma protuberans in the United States, 1973 to 2002. J Am Acad Dermatol. 2007;56(6):968-73.

4. Kreicher KL, Kurlander DE, Gittleman HR, Barnholtz-Sloan JS, Bordeaux JS. Incidence and survival of primary dermatofibrosarcoma protuberans in the United States. Dermatol Surg. 2016;42(Suppl 1):S24-31.

5. Bowne WB, Antonescu CR, Leung DH, Katz SC, Hawkins WG, Woodruff JM, Brennan MF, Lewis JJ. Dermatofibrosarcoma protuberans: a clinicopathologic analysis of patients treated and followed at a single institution. Cancer. 2000:88(12):2711-20.

6. Woo KJ, Bang SI, Mun GH, Oh KS, Pyon JK, Lim SY. Long-term outcomes of surgical treatment for dermatofibrosarcoma protuberans according to width of gross resection margin. J Plast Reconstr Aesthet Surg. 2016:69(3):395-401.

7. Trofymenko O, Bordeaux JS, Zeitouni NC. Survival in patients with primary dermatofibrosarcoma protuberans: National Cancer Database analysis. J Am Acad Dermatol. 2018;78(6):1125-34.

8. Larbcharoensub N, Kayankarnnavee J, Sanpaphant S, Kiranantawat K, Wirojtananugoon C, Sirikulchayanonta V. Clinicopathological features of dermatofibrosarcoma protuberans. Oncol Lett. 2016;11(1):661-7.

9. Gloster HM Jr. Dermatofibrosarcoma protuberans. J Am Acad Dermatol. 1996;35(3 Pt 1):355-74.

10. Noujaim J, Thway K, Fisher C, Jones RL. Dermatofibrosarcoma protuberans: from translocation to targeted therapy. Cancer Biol Med. 2015;12(4):375-84.

11. Penner DW. Metastasizing dermatofibrosarcoma protuberans; a case report. Cancer. 1951;4(5):1083-6.

12. Stacchiotti S, Pedeutour F, Negri T, Conca E, Marrari A, Palassini E, Collini P, Keslair F, Morosi C, Gronchi A, et al. Dermatofibrosarcoma protuberansderived fibrosarcoma: clinical history, biological profile and sensitivity to imatinib. Int J Cancer. 2011;129(7):1761-72.

13. Stacchiotti S, Astolfi A, Gronchi A, Fontana A, Pantaleo MA, Negri T, Brenca M, Tazzari M, Urbini M, Indio V, et al. Evolution of dermatofibrosarcoma protuberans to DFSP-derived fibrosarcoma: an event marked by epithelial-mesenchymal transition-like process and 22q loss. Mol Cancer Res. 2016;14(9):820-9.

14. Huis In't Veld EA, van Coevorden F, Grunhagen DJ, Smith MJ, van Akkooi ACJ, Wouters M, Hayes AJ, Verhoef C, Strauss DC, van Houdt WJ. Outcome after surgical treatment of dermatofibrosarcoma protuberans: is clinical follow-up always indicated? Cancer. 2019;125(5):735-41.

15. Liang CA, Jambusaria-Pahlajani A, Karia PS, Elenitsas R, Zhang PD, Schmults CD. A systematic review of outcome data for dermatofibrosarcoma protuberans with and without fibrosarcomatous change. J Am Acad Dermatol. 2014;71(4):781-6.

16. Li Y, Wang C, Yang K, Peng S, Wang Q, Chen S, Ji Y. Clinical features of dermatofibrosarcoma protuberans and risk factors for local recurrence after Mohs micrographic surgery. J Am Acad Dermatol. 2020;82:1219-21.

17. Li Y, Wang C, Xiang B, Chen S, Li L, Ji Y. Clinical features, pathological findings and treatment of recurrent dermatofibrosarcoma protuberans. J Cancer. 2017:8(7):1319-23.

18. Zurada JM. Introduction to artificial neural systems. Minnesota: West Publishing Company; 1992

19. Ma Z, Zhang W, Luo Z, Sun X, Li Z, Lin L. Ultrasonic characterization of thermal barrier coatings porosity through BP neural network optimizing Gaussian process regression algorithm. Ultrasonics. 2020;100:105981. 
20. Liu TY, Zhang P, Wang J, Ling YF. Compressive strength prediction of PVA fiber-reinforced cementitious composites containing nano- $-\mathrm{SiO}_{2}$ using $\mathrm{BP}$ neural network. Materials (Basel). 2020;13(3):521.

21. Park S, Cho S, Kim M, Park JU, Jeong EC, Choi E, Park JH, Lee C, Chang MS. Dermatofibrosarcoma protuberans: a retrospective study of clinicopathologic features and related Akt/mTOR, STAT3, ERK, cyclin D1, and PD-L1 expression. J Am Acad Dermatol. 2018;79(5):843-52.

22. Connelly JH, Evans HL. Dermatofibrosarcoma protuberans. A clinicopathologic review with emphasis on fibrosarcomatous areas. Am J Surg Pathol. 1992;16(10):921-5

23. Serra-Guillen C, Llombart B, Nagore E, Guillen C, Requena C, Traves V, Kindem S, Alcala R, Rivas N, Sanmartin O. Mohs micrographic surgery in dermatofibrosarcoma protuberans allows tumour clearance with smaller margins and greater preservation of healthy tissue compared with conventional surgery: a study of 74 primary cases. Br J Dermatol. 2015;172(5):1303-7.

24. Reha J, Katz SC. Dermatofibrosarcoma protuberans. Surg Clin North Am. 2016;96(5):1031-46

25. Acosta AE, Velez CS. Dermatofibrosarcoma protuberans. Curr Treat Options Oncol. 2017;18(9):56.

26. Lyu A, Wang Q. Dermatofibrosarcoma protuberans: a clinical analysis. Oncol Lett. 2018;16(2):1855-62.

27. Valdivielso-Ramos M, Torrelo A, Campos M, Feito M, Gamo R, RodriguezPeralto JL. Pediatric dermatofibrosarcoma protuberans in Madrid, Spain: multi-institutional outcomes. Pediatr Dermatol. 2014;31(6):676-82.

28. Rubio GA, Alvarado A, Gerth DJ, Tashiro J, Thaller SR. Incidence and outcomes of dermatofibrosarcoma protuberans in the US pediatric population. J Craniofac Surg. 2017;28(1):182-4.

29. Posso-De Los Rios CJ, Lara-Corrales I, Ho N. Dermatofibrosarcoma protuberans in pediatric patients: a report of 17 cases. J Cutan Med Surg. 2014:18(3):180-5.

30. Iqbal CW, St Peter S, Ishitani MB. Pediatric dermatofibrosarcoma protuberans: multi-institutional outcomes. J Surg Res. 2011;170(1):69-72.

31. Hisaoka M, Okamoto S, Morimitsu Y, Tsuji S, Hashimoto H. Dermatofibrosarcoma protuberans with fibrosarcomatous areas. Molecular abnormalities of the $\mathrm{p} 53$ pathway in fibrosarcomatous transformation of dermatofibrosarcoma protuberans. Virchows Arch. 1998;433(4):323-9.

32. Hiraki-Hotokebuchi Y, Yamada Y, Kohashi K, Yamamoto H, Endo M, Setsu $\mathrm{N}$, Yuki K, Ito T, Iwamoto Y, Furue M, et al. Alteration of PDGFRbetaAkt-mTOR pathway signaling in fibrosarcomatous transformation of dermatofibrosarcoma protuberans. Hum Pathol. 2017;67:60-8.

33. Valdivielso-Ramos M, Hernanz JM. Dermatofibrosarcoma protuberans in childhood. Actas Dermosifiliogr. 2012;103(10):863-73.

34. Lowe GC, Onajin O, Baum CL, Otley CC, Arpey CJ, Roenigk RK, Brewer JD. A comparison of Mohs micrographic surgery and wide local excision for treatment of dermatofibrosarcoma protuberans with long-term followup: The Mayo Clinic experience. Dermatol Surg. 2017;43(1):98-106.

35. Meguerditchian AN, Wang J, Lema B, Kraybill WG, Zeitouni NC, Kane JM 3rd. Wide excision or Mohs micrographic surgery for the treatment of primary dermatofibrosarcoma protuberans. Am J Clin Oncol. 2010:33(3):300-3.

36. Paradisi A, Abeni D, Rusciani A, Cigna E, Wolter M, Scuderi N, Rusciani L, Kaufmann R, Podda M. Dermatofibrosarcoma protuberans: wide local excision vs. Mohs micrographic surgery. Cancer Treat Rev. 2008:34(8):728-36.
37. DuBay D, Cimmino V, Lowe L, Johnson TM, Sondak VK. Low recurrence rate after surgery for dermatofibrosarcoma protuberans: a multidisciplinary approach from a single institution. Cancer. 2004;100(5):1008-16.

38. Gloster HM Jr, Harris KR, Roenigk RK. A comparison between Mohs micrographic surgery and wide surgical excision for the treatment of dermatofibrosarcoma protuberans. J Am Acad Dermatol. 1996;35(1):82-7.

39. Veronese F, Boggio P, Tiberio R, Gattoni M, Fava P, Caliendo V, Colombo E, Savoia P. Wide local excision vs. Mohs Tubingen technique in the treatment of dermatofibrosarcoma protuberans: a two-centre retrospective study and literature review. J Eur Acad Dermatol Venereol. 2017;31(12):2069-76.

40. Jia J, Zheng Y, Dong $X$, Wang $X$, Yang J, Ying Z, Wang Y, Niu X, Xiao S. Dermatofibrosarcoma protuberans with pit-like lesions: a case report and literature review. Oncol Lett. 2015;10(6):3765-8.

41. Abbott JJ, Oliveira AM, Nascimento AG. The prognostic significance of fibrosarcomatous transformation in dermatofibrosarcoma protuberans. Am J Surg Pathol. 2006;30(4):436-43.

42. Allen A, Ahn C, Sangueza OP. Dermatofibrosarcoma protuberans. Dermatol Clin. 2019;37(4):483-8.

43. Lemm D, Mugge LO, Mentzel T, Hoffken K. Current treatment options in dermatofibrosarcoma protuberans. J Cancer Res Clin Oncol. 2009;135(5):653-65.

44. Sasaki M, Ishida T, Horiuchi H, MacHinami R. Dermatofibrosarcoma protuberans: an analysis of proliferative activity, DNA flow cytometry and p53 overexpression with emphasis on its progression. Pathol Int. 1999:49(9):799-806.

45. Khor LY, Bae K, Paulus R, Al-Saleem T, Hammond ME, Grignon DJ, Che M, Venkatesan V, Byhardt RW, Rotman M, et al. MDM2 and Ki-67 predict for distant metastasis and mortality in men treated with radiotherapy and androgen deprivation for prostate cancer: RTOG 92-02. J Clin Oncol. 2009:27(19):3177-84.

46. Klapper W, Hoster E, Determann O, Oschlies I, van der Laak J, Berger F, Bernd HW, Cabecadas J, Campo E, Cogliatti S, et al. Ki-67 as a prognostic marker in mantle cell lymphoma-consensus guidelines of the pathology panel of the European MCL Network. J Hematop. 2009;2(2):103-11.

47. Hoster E, Rosenwald A, Berger F, Bernd HW, Hartmann S, Loddenkemper C, Barth TF, Brousse N, Pileri S, Rymkiewicz G, et al. Prognostic value of Ki-67 index, cytology, and growth pattern in mantle-cell lymphoma: results from randomized trials of the European mantle cell lymphoma network. J Clin Oncol. 2016;34(12):1386-94.

48. Zhao J, Tian H, Li DA. Channel prediction based on BP neural network for backscatter communication networks. Sensors (Basel). 2020;20(1):300.

49. Rumelhart H. Williams: learning representations by back-propagation errors. Nature. 1986;323:533-6.

50. Parker DB. Learning = logic: casting the cortex of the human brain in silicon. Technical Report Tr-47. Center for Computational Research in Economics and Management Science. MIT, Cambridge, MA; 1985.

51. Cun YL. Une procedure d'apprentissage pour reseau a seuil assy metrique. Cognitiva. 1985;85:599-604.

\section{Publisher's Note}

Springer Nature remains neutral with regard to jurisdictional claims in published maps and institutional affiliations.

Ready to submit your research? Choose BMC and benefit from:

- fast, convenient online submission

- thorough peer review by experienced researchers in your field

- rapid publication on acceptance

- support for research data, including large and complex data types

- gold Open Access which fosters wider collaboration and increased citations

- maximum visibility for your research: over 100M website views per year

At BMC, research is always in progress.

Learn more biomedcentral.com/submissions 